\title{
Prenatal ultrasound evaluation in the current era of COVID-19 - looking only for major congenital defects or subtle sonographic and echocardiographic findings, as well?
}

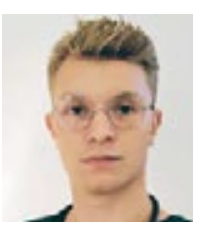

\author{
Oskar Sylwestrzak ID, Maria Respondek-Liberska ${ }^{2,3}$ ID \\ 'Medical Faculty, Fifth-grade student, Medical University of Lodz, Poland \\ 2Department of Prenatal Cardiology, Polish Mother's Memorial Hospital Research Institute in Lodz, Poland \\ ${ }^{3}$ Department of Diagnosis and Prophylaxis of Congenital Malformations, Medical University of Lodz, Poland
}

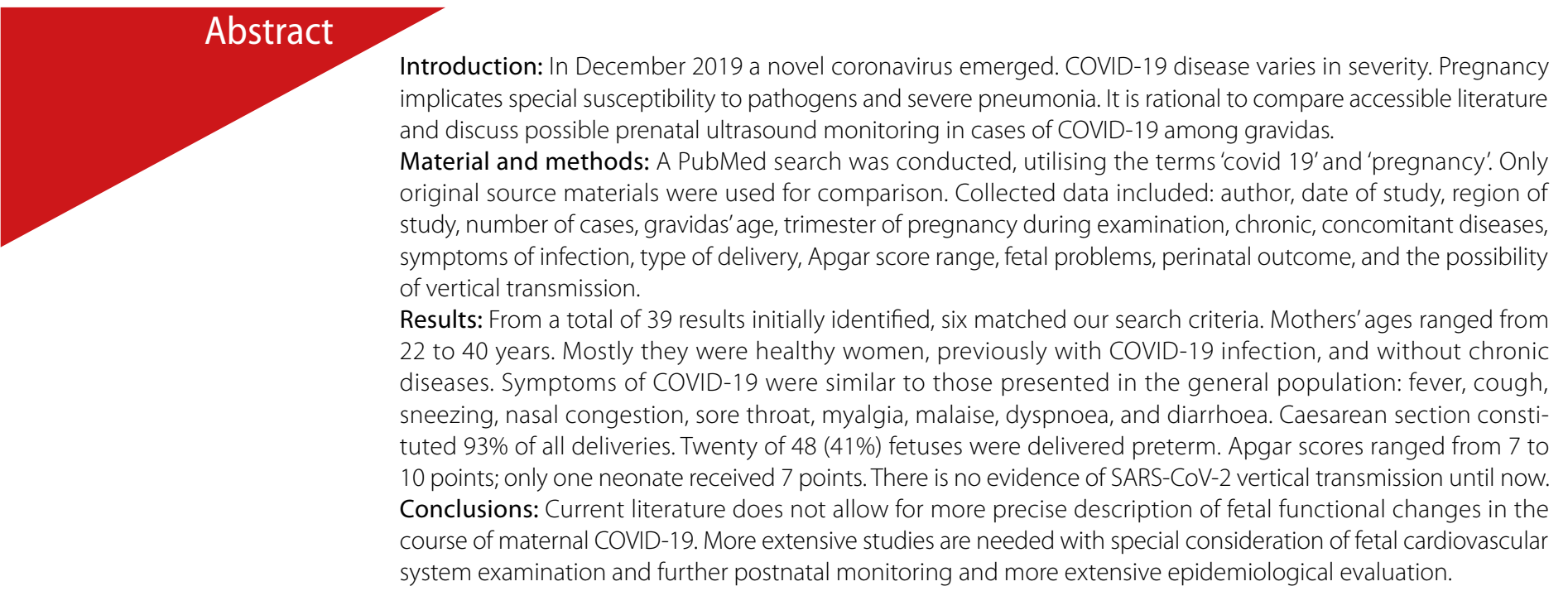

Key words: fetal echocardiography, fetal ultrasound, COVID-19.

\author{
Corresponding author: \\ Oskar Sylwestrzak \\ Medical Faculty \\ Medical University of Lodz, Poland \\ e-mail: sylwestrzakoskarpatryk@gmail.com
}

\section{Introduction}

In December 2019 a novel coronavirus, called SARS-CoV-2 emerged in China. From 10-24 January 2020, the number of people diagnosed with SARS-CoV-2 infection in China incre- ased by 31.4 times [1]. The COVID-19 disease has widely occurred across the globe, causing significant public health and economic problems. At the time of preparing this article, COVID-19 has slowed down in China, but is aggressively spreading in Europe and North America. The pandemic is still 
present. Currently there have been 846,251 confirmed cases and 41,482 people have died because of COVID-19 [2].

In Poland, we have had 2311 cases and 33 people have died [2]. The Polish government has restricted social life, for example by forbidding travelling of more than two people together, except families [3]. Mostly older men are infected (Li et al. average 59 years old, 56\% men) [4], so a prevalently adult affected population is described in literature, also because of more aggressive course of the disease. But now that there are more than 800,000 cases, pregnant women are being discussed, because of not only the theoretical but also the real possibility of infection. Pregnancy implicates an immunosuppressive state and physiological changes (diaphragm elevation, increased oxygen consumption, and oedema of respiratory tract mucosa), which cause susceptibility to pathogens and severe pneumonia.

The 1918 influenza pandemic caused a mortality rate of $2.6 \%$ in the overall population but $37 \%$ among pregnant women. In the more recent H1N1 influenza virus pandemic in 2009 pregnant women were four times more likely to be admitted to hospital than the general population. Moreover, around 33\% of pregnant women with SARS (caused by SARS-CoV) required mechanical ventilation, and the mortality rate was as high as $25 \%$ for these women [5].

For now, no publication concerning infected pregnant women in Poland is available on PubMed, probably because of the less critical situation compared to other countries. The authors of this article are concerned that this is only a matter of time, unfortunately. Due to the above, it is rational to compare accessible literature and discuss possible prenatal ultrasound monitoring in cases of COVID-19 among gravidas.

The aim of this study was to evaluate the influence of COVID-19 on the course of pregnancy. On the basis of such analysis, we tried to answer whether during the COVID-19 pandemic it is possible to provide detailed fetal ultrasound and echocardiographic examination to high-risk pregnant women.

\section{Material and methods}

A PubMed search was conducted from recent publications. In order to identify all potentially relevant articles regarding the influence of COVID-19 on the course of pregnancy, the search was performed utilising the terms 'covid 19' and 'pregnancy'. Potentially relevant articles were evaluated. Only fullsize articles of English language published in journals or during press processes were considered. Only original source materials were used for comparison of COVID-19 infected pregnant women.

Studies reporting single case reports were not considered. Also, cases not diagnosed by laboratory tests for SARS-CoV-2 were excluded. Collected data included: author, date of study, region of study, number of cases, gravidas' age, trimester of pregnancy during examination, chronic, concomitant diseases, symptoms of infection, type of delivery, Apgar score range, $\mathrm{fe}$ tal problems, perinatal outcome, and the possibility of vertical transmission. Other results were used for discussion.

\section{Results}

From a total of 39 results initially identified, six matched our search criteria for original source material with more than one case report described and English language publication. Three studies were available in Chinese language, two studies presented single case reports, and two studies did not confirm all of the cases by laboratory tests for SARS-CoV-2. The individual original source study characteristics are given in Table 1 [5-10]. The studies originate from the China region between December 2019 and February 2020. In total the study included 55 pregnant women - 56 fetuses (two twins). Only one study described infected gravidas before the third trimester, but perinatal outcome was available only for third trimester fetuses.

The mothers' minimal age was 22 years and maximal age was 40 years. Mostly they were: previous to COVID-19 infection, healthy women, and without any chronic disease (one gestational hypertension, one gestational diabetes, one preeclampsia, one thalassemia with gestational diabetes, one after tricuspid and mitral valvular replacement, one complete placenta previa, one hypothyroidism, one polycystic ovary syndrome, one H1N1 coinfection, one Legionella pneumophila coinfection, and three uterine scars). Symptoms of COVID-19 were similar to those presented by the general population: fever, cough, sneezing, nasal congestion, sore throat, myalgia, malaise, dyspnoea, and diarrhoea. Caesarean section constituted $93 \%$ of all deliveries. Twenty of 48 (41\%) fetuses were delivered preterm. Apgar scores ranged from 7 to 10 points; only one neonate received 7 points.

\section{Discussion}

Since December 2019, unexplained cases of pneumonia were reported in Wuhan, China. The pathogen was discovered to be new and was named by the World Health Organisation (WHO) as coronavirus 2019-nCoV. Later, the coronavirus study group of the International Committee on Taxonomy of Viruses named 2019-nCoV as severe acute respiratory syndrome coronavirus 2 (SARS-CoV-2) [1]. At present the pandemic is spreading, with higher and higher mortality in Europe; however, original source materials are available only from China, to date.

According to the $\mathrm{WHO}$, a suspect case is:

- A patient with acute respiratory illness (fever and at least one sign/symptom of respiratory disease, e.g. cough, shortness of breath), and a history of travel to or residence in a location reporting community transmission of COVID-19 disease during the 14 days prior to symptom onset; or

- A patient with any acute respiratory illness and having been in contact with a confirmed or probable COVID-19 case (see definition of contact) in the last 14 days prior to symptom onset; or

- A patient with severe acute respiratory illness (fever and at least one sign/symptom of respiratory disease, e.g. cough, shortness of breath; and requiring hospitalisation) AND the absence of an alternative diagnosis that fully explains the clinical presentation [11]. 


\begin{tabular}{|c|c|c|c|}
\hline 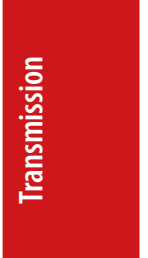 & 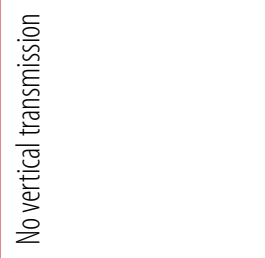 & 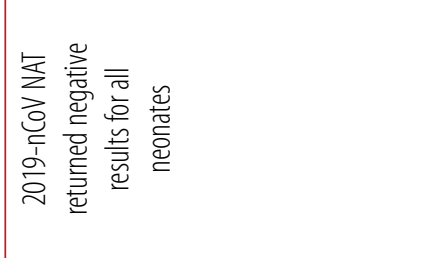 & 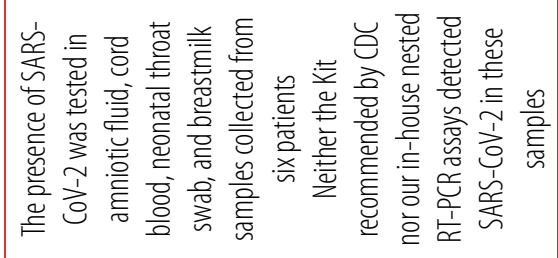 \\
\hline 善 & 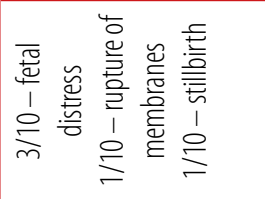 & 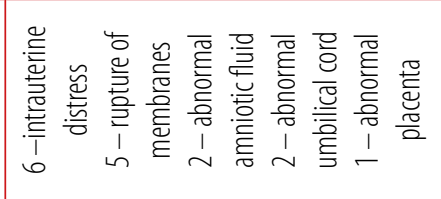 & 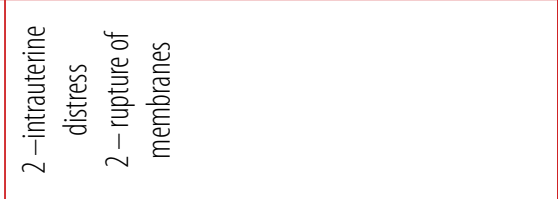 \\
\hline 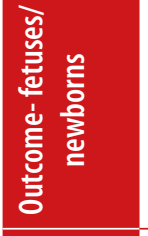 & 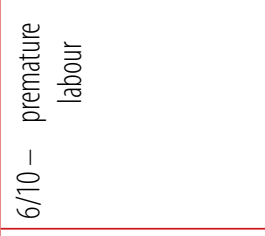 & 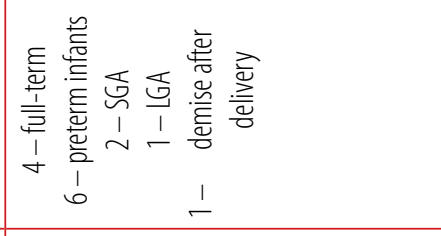 & 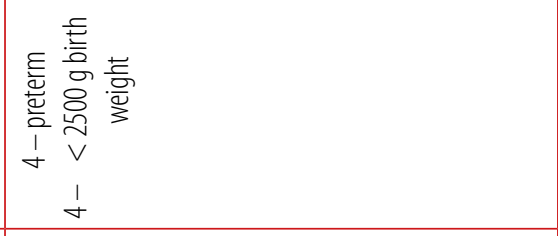 \\
\hline 产 & $\circ$ & 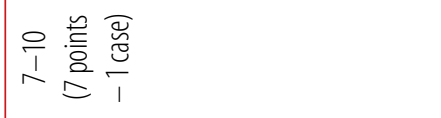 & $\underset{0}{0}$ \\
\hline 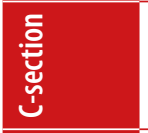 & $\stackrel{0}{\circ}$ & $\stackrel{\Omega}{N}$ & $\frac{\Omega}{\alpha}$ \\
\hline 言 & 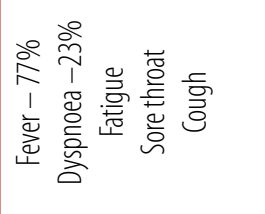 & 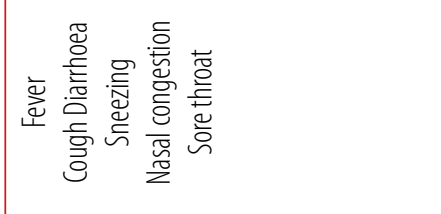 & 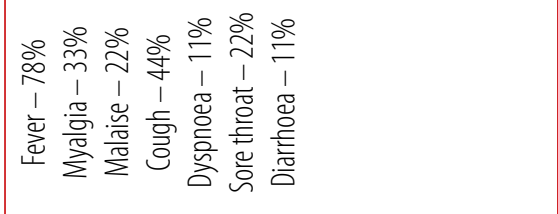 \\
\hline 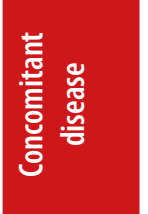 & 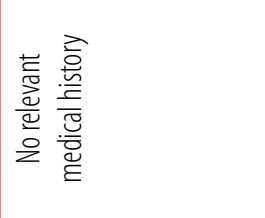 & 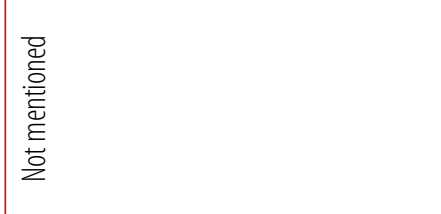 & 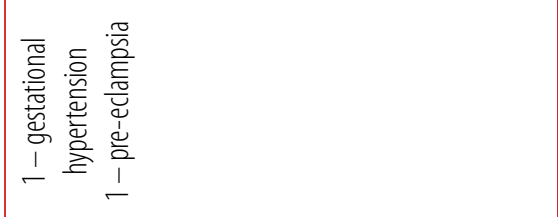 \\
\hline 离 을 흘 & 忘 & 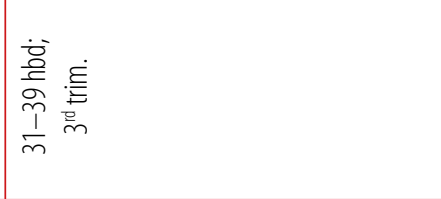 & 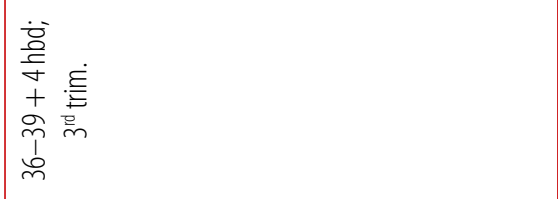 \\
\hline 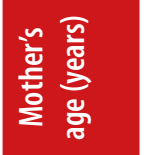 & 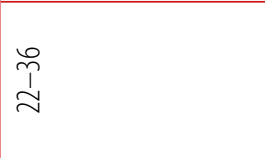 & 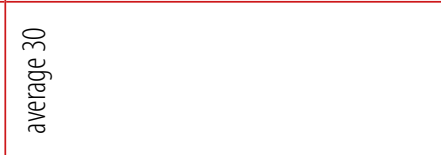 & $\begin{array}{l}9 \\
0 \\
0 \\
d\end{array}$ \\
\hline 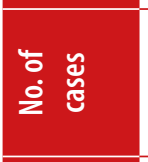 & $m$ & 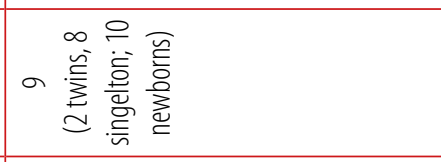 & a \\
\hline 흥 & 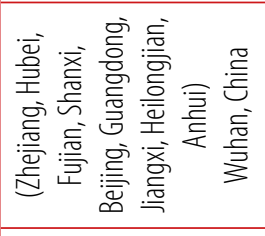 & 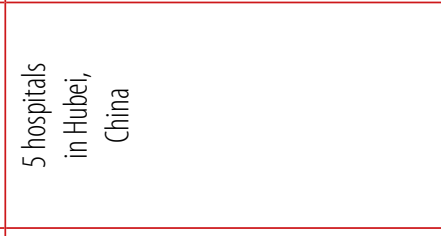 & 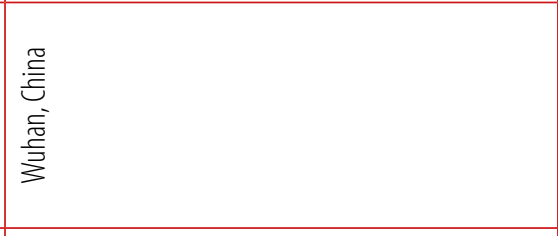 \\
\hline ััّ & 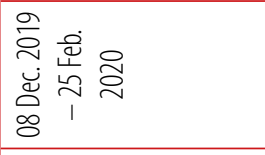 & 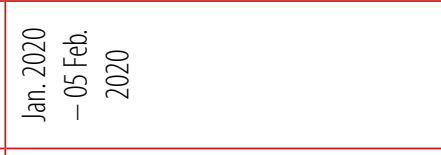 & 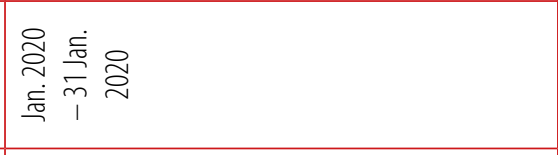 \\
\hline 毫 & 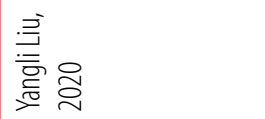 & 堊空 & 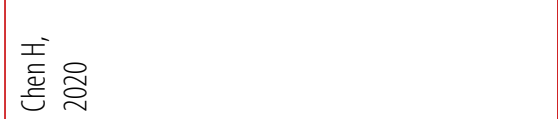 \\
\hline
\end{tabular}




$$
\mid
$$


Table 2. Ultrasound and echocardiographic markers of fetal viral infections

\begin{tabular}{|c|c|c|}
\hline Virus & Ultrasound findings & $\begin{array}{l}\text { Echocardiographic features which may indicate } \\
\text { fetal viral infection }\end{array}$ \\
\hline Rubella & $\begin{array}{l}\text { - Obstetrics ultrasound: micrognathia, microcephaly, microphthalmos, } \\
\text { bony radiolucencies, intra-uterine growth restriction, hepatomegaly, } \\
\text { splenomegaly, calcification of placenta, liver, brain, spinal cord, eyes, } \\
\text { kidneys, and musculoskeletal system, cleft lip, } \\
\text { - Fetal echocardiography recommended }\end{array}$ & \multirow{7}{*}{$\begin{array}{l}\text { - Fetal cardiomegaly } \\
\text { - Fetal heart hypertrophy } \\
\text { - Pericardial effusion } \\
\text { - Myocardial hypokinesis } \\
\text { - Increased echogenicity of the valves } \\
\text { - Increased echogenicity of endocardium } \\
\text { - Bright spot or bright spots } \\
\text { - Functional regurgitations (most often tricuspid valve } \\
\text { regurgitation) } \\
\text { - Ductus arteriosus constriction } \\
\text { - Premature closure of the foramen ovale } \\
\text { - Dilatation of the coronary arteries } \\
\text { - Fetal heart arrhythmias } \\
\text { - Tachycardia } \\
\text { - Bradycardia }\end{array}$} \\
\hline Cytomegalovirus (CMV) & $\begin{array}{l}\text { - Obstetrics ultrasound: microcephaly, cerebellar aplasia, intra-uterine } \\
\text { growth restriction, hydrops fetalis, ascites, periventricular calcifications, } \\
\text { hydrocephalus, liver calcification, hepatomegaly, splenomegaly, retinal } \\
\text { calcification, diffuse placental inflammation } \\
\text { - Fetal echocardiography recommended }\end{array}$ & \\
\hline Herpes simplex virus (HSV) & $\begin{array}{l}\text { - Obstetrics ultrasound: intra-uterine growth restriction, hepatomegaly, } \\
\text { microcephaly, periventricular and placental calcifications, microcephaly, } \\
\text { hydrocephaly, cerebral atrophy } \\
\text { - Fetal echocardiography recommended }\end{array}$ & \\
\hline Parvovirus B19 & $\begin{array}{l}\text { - Obstetrics ultrasound: hydrops fetalis, oedematous skin, ascites, pleural } \\
\text { effusion, hepatomegaly, splenomegaly, hydrocephaly, calcification of } \\
\text { liver and spleen, eye abnormalities, anencephaly } \\
\text { - Fetal echocardiography recommended }\end{array}$ & \\
\hline Varicella zoster virus & $\begin{array}{l}\text { - Obstetrics ultrasound: placental calcification, retinal and intracranial } \\
\text { calcification, intra-uterine growth restriction, limb deformities, skin } \\
\text { scarring, microcephaly, hepatomegaly, splenomegaly } \\
\text { - Fetal echocardiography recommended }\end{array}$ & \\
\hline Coxsackie viruses B1 and B5 & $\begin{array}{l}\text { - Obstetrics ultrasound: urogenital malformations, gastrointestinal } \\
\text { malformations, central nervous system destruction- not associated } \\
\text { with chromosomal anomalies or genetic syndromes } \\
\text { - Fetal echocardiography recommended }\end{array}$ & \\
\hline Influenza & $\begin{array}{l}\text { - Obstetrics ultrasound: pneumonitis, pleural effusion, intra-uterine } \\
\text { growth restriction } \\
\text { - Fetal echocardiography recommended }\end{array}$ & \\
\hline
\end{tabular}

This statement is consistent with most common patients' symptoms: fever, cough, dyspnoea, etc. [1]. Our analysis showed that these symptoms are also present in pregnant women, who do not experience any other characteristic complaints. Diarrhoea affects approximately $3 \%$ of cases with COVID-19 in the general population [1]. However, Chen et al. noted a higher incidence in gravidas (11\%) [5]. Any suspected case should be tested for SARS-CoV-2, using available tests, such as quantitative reverse transcription polymerase chain reaction (RT-PCR). In pregnant women a CT scan is essential not only for evaluation of the clinical condition, but also may be used as a primary tool for detection of COVID-19 in epidemic areas [12]. A chest CT scan of a COVID-19 patient shows characteristic features in the disease process in lungs and has high sensitivity and speed for diagnosis [13]. Adverse effects of radiation exposure (> $610 \mathrm{mGy}$ ) for fetuses are well-known, for example: fetal growth restriction, microcephaly, or intellectual disability [14], so a minimal number of CT scans, lead blankets on the lower abdomen and pelvis (uterus), and low-dose imaging mode should have been, and indeed were, used in the evaluated studies $[6,12]$.

Topical articles are focused on the maternal state but lack detailed fetal description. It is worth to discussing whether
COVID-19 maternal infection should be indication for further, more specific fetal ultrasound. Scientists and experts agree that fetal monitoring should be conducted using ultrasonography $[12,14]$. Ultrasound assessment of fetal growth, amniotic fluid volume, umbilical artery Doppler, and fetal heart rate should be checked $[12,14]$. More advanced monitoring is recommended once the fetus reaches viability [14]. Other viral fetal infections co-occur with prenatal symptoms, which can be detected by ultrasonography (Table 2) [15-18]. Ye et al. presented a study suggesting that maternal viral infection is significantly associated with risk of congenital heart defect in offspring [19]. Viruses such as cytomegalovirus (CMV) and rubella virus can cause transplacental infection. Other viruses are occasionally able to gain access to the fetus via the hematogenous route. Herpes simplex virus (HSV), varicella zoster virus (VZV), and Coxsackievirus are among those that can cross the placental barrier and infect the fetus [16]. Until now, no characteristic fetal symptoms of COVID-19 have been described. Moreover, there are no data showing that SARS-CoV-2 is able to cross the feto-maternal protective barrier and cause fetal viraemia, and no evidence of SARS-CoV-2 vertical transmission was found in the analysed manuscripts [5-10]. However, we have to re- 
Table 3. Routine elements of fetal echocardiographic examination

\begin{tabular}{|l|l|}
\hline $\begin{array}{l}\text { Separate elements of } \\
\text { examination }\end{array}$ & Additional fetal echocardiography elements \\
& Time of examination: $>45$ min, about $1-1.5 \mathrm{~h}$ \\
& Techniques: colour Doppler, spectral Doppler, power Doppler, power angio, \\
& M-Mode, tissue M-Mode, 3D, 4D \\
& Detailed examination of: atria, ventricles, foramen ovale and its flap, valves: \\
& mitral, tricuspid, aortic, pulmonary, pulmonary trunk, aortic arch, isthmus, \\
& descending aorta, pulmonary arteries, superior vena cava, inferior vena cava, \\
& intraventricular septum, ductus venosus, ductus arteriosus, umbilical arteries and \\
& vein, upper mediastinum, thymus \\
& Parameters: AP (transverse heart diameter), shortening fraction, TEl index, \\
& Pulsatility index, Resistance index, TAPSE, MAPSE \\
\hline
\end{tabular}

member that maternal viral infections do not need to bypass the placental barrier to affect fetal development [20]. According the guidance, suspected, probable, or confirmed cases of COVID-19 should be managed by tertiary hospitals [12]. These recommendations preserve the unpredictable COVID-19 course in pregnant women and enable, from the logistic point of view, more complex perinatal care. At this point the authors would like to highlight the special importance of fetal heart and cardiovascular system examination. One of the methods of fetal monitoring is targeted echocardiography, which, with high probability, predicts normal fetal development before and after delivery [21]. Fetal echocardiographic examination contains basic obstetrical screening in addition to elaborate cardiovascular assessment (Table 3) [22]. This examination requires direct contact between the patient and an experienced echocardiographer and lasts at least $45 \mathrm{~min}$ [22]. Basic obstetric screening (15-20-min scan) might detect major congenital anomalies, both cardiac and extracardiac. Detection of subtle sonographic findings is dedicated for echocardiography and requires more time and more experience. Rimmer et al. contraindicate, for

Table 4. Indications for emergency fetal echocardiography during the COVID-19 pandemic

\section{Major indications for fetal echocardiography}

Congenital heart defect or extracardiac defect

Fetal ascites or hydrothorax or severe pericardial effusion $(>5 \mathrm{~mm}$ )

Fetal heart arrhythmias (FHR $>180$ beats/min and $<100$ beats/min)

Twin pregnancy with asymmetric twins $>25 \%$

Table 5. Polish Registry for Fetal Cardiac Malformations www.orpkp.pl for 2020-2021

\section{Aims of orpkp.pl for years 2020-2021}

Any differences in the number of affected fetuses in comparison with 2018-2019?

Any differences in types of heart defects, arrhythmias, or other problems?

Any differences in premature deliveries?

Any differences in caesarean sections versus vaginal deliveries?

Any differences in geographic areas for clusters of heart defects? women (medical workers: doctors, nurses, etc.) who are more than 28 weeks pregnant, direct contact with patients, in order not to be infected [23]. Considering the pandemic state, should also prenatal echocardiographers limit their examination only to basic measurements or totally confine their work? It may occur that more detailed analysis is impossible. In the authors' department, which is part of a Polish tertiary centre for pregnant women, in the era of the COVID-19 pandemic, full examinations are provided for special cases, due to limited human resources and other emergent reasons. Currently we have four major indications for fetal echocardiography (Table 4): congenital heart defect or extracardiac defect (as fetal heart will tell us about the fetal condition and its short-term and long-term prognosis); fetal ascites or hydrothorax or severe pericardial effusion ( $>5 \mathrm{~mm}$ ); fetal heart arrhythmias (FHR $>180 / \mathrm{min}$ and $<100$ beats/min), and twin pregnancy with asymmetric twins $>25 \%$. Presumably, the impact of SARSCoV-2 on fetal life will be better understood in a few years, after a series of tests (echocardiography, eye test, hearing test, psychological evaluation, etc.), not among fetuses, but among infants, children, and adolescents. Here arises the probable need for further tertiary monitoring of newborns touched by maternal SARS-CoV-2 infection. For now, the prognosis for fetuses whose mothers were infected with SARS-CoV-2 is good, but still there are too few data, and, as we know, prenatal viral infections might be connected with poor outcome [24]. To date, COVID-19 concerns mainly the third trimester. First and second trimester infection is a current problem, which is growing before us. Further studies with postnatal follow-ups are needed because as yet there are no available data.

COVID-19 itself is not an indication for special delivery timing and mode, unless there are maternal indications like persistent hypoxia requiring improvement [12]. A high rate of C-section deliveries was noted (93\%), but the reason was not provided in all studies. Di Mascio et al. also noted higher rate of caesarean sections among COVID-19 pregnant women than in the general population [25]. In the case of COVID-19 there is no clear benefit of $\mathrm{C}$-section, and treatment during pregnancy should be profoundly deliberated [14].

In the era of COVID-19 the Polish National Registry for Cardiac Problems (www.orpkp.pl) [26] is of special value, operating under the auspices of the Polish Prenatal Cardiology Society. Al- 
though this registry (existing for the last 15 years) is not obligatory, it could be a good source of data from the obstetricians and fetal cardiologists in our country, who would devote their efforts and time to share their cases with us for future analysis. Together, we could answer unsolved questions (Table 5). In the time of COVID-19 the Tricefy 4 company is offering hospitals around the world the possibility to join efforts and communication via the cloud. Their program is excellent and worthy of strong recommendation from our side, because the Department of Prenatal Cardiology of the Polish Mother's Memorial Hospital, Research Institute in Lodz is the first Polish user of this program in our country. Communication via internet and medical consultations of fetal heart movies were never so easy and clear.

\section{Conclusions}

The authors present data from a literature research of pregnant women infected by SARS-CoV-2. COVID-19 pregnant women should be managed with special concern because maternal infection is known to have influenced maternofetal wellbeing in previous pandemics. The current literature does not allow for more precise description of fetal functional changes in the course of maternal COVID-19. More extensive studies are needed with special consideration of fetal cardiovascular system examination and further postnatal monitoring and more extensive epidemiological evaluation.

\section{Conflict of interest}

The authors declare no conflict of interest.

\section{REFERENCES}

1. Sun P, Lu X, Xu C, Sun W, Pan B. Understanding of COVID-19 based on current evidence. J Med Virol 2020; https://doi.org/10.1002/jmv.25722

2. https://www.worldometers.info/coronavirus/

3. https://www.gov.pl/web/koronawirus/

4. Li Q, Guan X, Wu P, et al. Early transmission dynamics in Wuhan, China, of novel coronavirus-infected pneumonia. N Engl J Med 2020; 382: 1199-1207.

5. Chen $\mathrm{H}$, Guo J, Wang $\mathrm{C}$, et al. Clinical characteristics and intrauterine vertical transmission potential of COVID-19 infection in nine pregnant women: a retrospective review of medical records. Lancet 2020; 395: 809815. [published correction appears in Lancet 2020; 395:1038]

6. Liu D, Li L, Wu X, et al. Pregnancy and perinatal outcomes of women with coronavirus disease (COVID-19) pneumonia: a preliminary analysis. Am J Roentgenol 2020; 18: 1-6.

7. Liu Y, Chen H, Tang K, Guo Y. Clinical manifestations and outcome of SARS-CoV-2 infection during pregnancy. J Infec 2020; doi: 10.1016/j. jinf.2020.02.028.

8. Zhu H, Wang L, Fang C, et al. Clinical analysis of 10 neonates born to mothers with 2019-nCoV pneumonia. Transl Pediatr 2020; 9: 51-60.

9. Fan C, Lei D, Fang C, et al. Perinatal transmission of COVID-19 Associated SARS-CoV-2: should we worry? Clin Infect Dis 2020; doi:10.1093/ $\mathrm{cid} / \mathrm{ciaa226.}$

10. Yu N, Li W, Kang Q, et al. Clinical features and obstetric and neonatal outcomes of pregnant patients with COVID-19 in Wuhan, China: a retrospective, single-centre, descriptive study. Lancet Infect Dis 2020; doi:10.1016/ S1473-3099(20)30176-6.

11. WHO. Global surveillance for COVID-19 disease caused by human infection with the 2019 novel coronavirus. Interim guidance. 27 February 2020 https://www.who.int/publications-detail/global-surveillance-for-humaninfection-with-novel-coronavirus-(2019-ncov) [Accessed 7 March 2020].
12. Poon LC, Yang H, Lee JCS, et al. ISUOG Interim Guidance on 2019 novel coronavirus infection during pregnancy and puerperium: information for healthcare professionals. Ultrasound Obstet Gynecol 2020; doi:10.1002/ uog. 22013

13. Ai T, Yang Z, Hou H, et al. Correlation of chest CT and RT-PCR testing in coronavirus disease 2019 (COVID-19) in China: a report of 1014 cases. Radiology 2020; doi:10.1148/radiol.2020200642.

14. Chen D, Yang H, Cao Y, et al. Expert consensus for managing pregnant women and neonates born to mothers with suspected or confirmed novel coronavirus (COVID-19) infection. Int J Gynecol Obstet 2020; doi:10.1002/ijgo.13146

15. Yagel S, Silverman NH, Gembruch U. Fetal Cardiology: Embryology, Genetics, Physiology, Echocardiographic Evaluation, Diagnosis, and Perinatal Management of Cardiac Diseases. $3^{\text {rd }}$ Edition. CRC Press, 2018.

16. Bailão LA, Osborne NG, Rizzi MC, Bonilla-Musoles F, Duarte G, Bailão TC. Ultrasound markers of fetal infection part 1: viral infections. Ultrasound Q 2005; 21: 295-308.

17. Crino JP, Driggers RW. Ultrasound findings associated with antepartum viral infection. Clin Obstet Gynecol 2018; 61: 106-121.

18. Respondek-Liberska M. Diagnostyka prenatalna USG/ECHO. Zaburzenia czynnościowe w układzie krążenia płodu. 1st Edition. Wydawnictwo PZWL, 2019.

19. Ye Z, Wang L, Yang T, et al. Maternal viral infection and risk of fetal congenital heart diseases: a meta-analysis of observational studies. J Am Heart Assoc 2019; 8: e011264.

20. Racicot K, Mor G. Risks associated with viral infections during pregnancy. J Clin Invest 2017; 127: 1591-1599.

21. Strzelecka I, Michalska E, Zych-Krekora K, Respondek-Liberska M. Follow-up on 107 fetuses with normal US + Echo after 37th week of gestation. Prenat Cardio 2017; 1: 26-30.

22. Respondek-Liberska M. Kardiologia prenatalna dla położników i kardiologów dziecięcych. 1st Edition. Wydawnictwo Czelej, 2006.

23. Rimmer A. COVID-19: doctors in final trimester of pregnancy should avoid direct patient contact. BMJ 2020; 368: $\mathrm{m} 1173$.

24. Maruyama Y, Sameshima H, Kamitomo M, et al. Fetal manifestations and poor outcomes of congenital cytomegalovirus infections: possible candidates for intrauterine antiviral treatments. J Obstet Gynaecol Res 2007; 33: 619-623.

25. Di Mascio D, Khalil A, Saccone G, et al. Outcome of coronavirus spectrum infections (SARS, MERS, COVID 1-19) during pregnancy: a systematic review and meta-analysis. Am J Obstet Gynecol MFM 2020; doi:10.1016/j. ajogmf.2020.100107.

26. Kordjalik P, Radzymińska-Chruściel B, Słodki M, et al. The Polish National Registry for Fetal Cardiac Pathology (www.orpkp.pl) - selected data analysis for 2013 and 2014 and comparison with data from 2004 to 2012. Prenat Cardio 2015; 5: 6-12.

\section{Division of work:}

Oskar Sylwestrzak (ORCID: 0000-0001-9325-7304): research concept and design, collection and/or assembly of data, data analysis and interpretation, writing the article, critical revision of the article, final approval of article

Maria Respondek-Liberska (ORCID: 0000-0003-0238-2172): data analysis and interpretation, writing the article, critical revision of the article, final approval of article 